\title{
Ultrastructural changes in the theca interna during follicular atresia in sheep*
}

\author{
J. D. O’Shea†, Mary F. Hay and D. G. Cran \\ Agricultural Research Council Institute of Animal Physiology, Animal Research Stntion, \\ 307 Huntingdon Road, Cambridge CB3 OJQ, U.K.
}

\begin{abstract}
Summary. Sixteen antral follicles, $1.8-4.2 \mathrm{~mm}$ in diameter, at various stages of atresia, were studied by electron microscopy. Deletion of theca interna cells by condensation followed by fragmentation (apoptosis), with subsequent engulfment of the fragments by remaining thecal cells, was present at all stages, but was most marked during secondary and tertiary atresia. In primary and secondary atresia, the relative numbers of thecal cells whose cytoplasm was rich in tubular endoplasmic reticulum were higher than in non-atretic follicles of comparable size. During tertiary atresia the number of cell layers in the theca interna was reduced, and cells rich in tubular endoplasmic reticulum became proportionately less numerous. Degenerating cellular material was present within the lumina of thecal capillaries at all stages of atresia. Such material was rarely seen in primary atresia, and increased in incidence progressively in later stages. It was concluded that during atresia a large number of theca interna cells are deleted by apoptosis, and many thecal capillaries become blocked with cellular debris.
\end{abstract}

\section{Introduction}

The fate of the theca interna of atretic ovarian follicles varies between species and depends to some extent on the stage of follicular development at which atresia commences (Brambell, 1956; Mossman \& Duke, 1973). Hypertrophy of the thecal cells has been observed in most species studied. These cells have variously been reported as subsequently forming corpora lutea atretica (Brambell, 1956) or being incorporated into glandular interstitial tissue (Mossman \& Duke, 1973). In the ovary of the ewe, however, neither of these tissues is normally present and in this species signs of thecal degeneration during the later stages of atresia have been observed (Hay, Cran \& Moor, 1976). Furthermore, the capillary network adjacent to the basal lamina of the membrana granulosa becomes significantly reduced as atresia progresses (Hay et al., 1976), and it has been suggested that changes in the thecal microcirculation may play a key role in atresia.

It was the purpose of the present study to examine in detail the nature of the changes in the cells and capillaries of the theca interna of atretic antral follicles of sheep, and to relate the timing of onset and progression of these changes to the previously reported changes in the membrana granulosa.

\section{Materials and Methods}

Sixteen atretic follicles, $1 \cdot 8-4 \cdot 2 \mathrm{~mm}$ in diameter, were studied. These follicles were rapidly dissected from ovaries removed under sodium pentobarbitone and fluothane anaesthesia from 6 Welsh mountain ewes on Days 13 or 14 of the oestrous cycle. Following dissection from the ovary, the follicles were fixed intact in $4 \%$ glutaraldehyde in $0.2 \mathrm{M}$-collidine buffer, $\mathrm{pH} 7 \cdot 2$, cut into segments after a brief period of immersion in the fixative and processed for electron microscopy as described by Hay et al. (1976). Thin sections were stained in uranyl acetate and lead citrate. Thick $(1 \mu \mathrm{m})$ sections for light microscopy were stained in $1 \%$ toluidine blue in $1 \%$ borax.

* Reprint requests to Dr M. F. Hay.

$\dagger$ Present address: Department of Veterinary Preclinical Sciences, University of Melbourne, Parkville, Victoria 3052, Australia. 
Each follicle was examined by light microscopy and classified into one of three stages of atresia by the criteria of Hay et al. (1976): follicles with occasional free pyknotic nuclei along the antral border were considered as being in the primary stage of atresia (4 follicles, $2.0-2.9 \mathrm{~mm}$ in diameter); in secondary atresia, free pyknotic nuclei were numerous and some had fused to form larger atretic bodies ( 5 follicles, $2 \cdot 1-2 \cdot 8 \mathrm{~mm}$ ); in the tertiary stage of atresia, cellular degeneration was widespread throughout the granulosa layer which was often partly detached from the underlying theca ( 7 follicles, $1 \cdot 8-4 \cdot 2 \mathrm{~mm}$ ). Differential cell counts were performed on low-power electron micrographs of the theca interna, as described by O'Shea, Cran, Hay \& Moor (1978), on at least 3 follicles from each grade of atresia and included 366, 301 and 293 cells respectively in the three grades; only cells in which nuclei were visible were counted.

\section{Results}

\section{Changes in theca cells}

In primary atresia, the structure of the theca interna was similar to that in non-atretic follicles of comparable size, as described previously (O'Shea et al., 1978), and consisted of about 8-12 layers of somewhat flattened, closely-packed cells. However, cells whose cytoplasm was rich in tubular endoplasmic reticulum (ER), regarded as putative steroidogenic cells (O'Shea et al., 1978), formed approximately $40 \%$ of the total and therefore were relatively about twice as numerous as in nonatretic follicles of similar size.

Degenerative changes were present in a very few thecal cells in primary atresia, but became widespread during secondary atresia. These changes were of the type described as apoptosis by Kerr, Wyllie \& Currie (1972). They consisted of nuclear and cytoplasmic condensation, nuclear and cellular fragmentation, and ultimate phagocytosis and degradation of the resultant cell fragments (PI. 1, Figs 1, 2 and 3). Cells undergoing such degeneration were randomly distributed throughout the theca interna, and surrounded by cells of normal structure. Foci of necrosis were not seen.

Phagocytosis of cell fragments (apoptotic bodies) was clearly a function of neighbouring viable thecal cells, including those rich in tubular ER, and no thecal invasion by macrophages was detected in the early stages of atresia. In view of the degree of change in most of the cell fragments, it was seldom possible to identify the nature of the cells undergoing degeneration. However, some of these fragments contained large amounts of tubular ER and were probably derived from cells of the same structural type. Other fragments, containing few cytoplasmic organelles, may have been derived from cells of less differentiated types.

\section{EXPLANATION OF PLATE 1}

Fig. 1. A single theca interna cell from a $2.6 \mathrm{~mm}$-diameter follicle in secondary atresia showing the initial stage of apoptosis. Six distinct nuclear fragments $(\mathrm{N})$ are present, some still joined by the outer membrane of the nuclear envelope (arrows); crescentic margination of chromatin is apparent. The cytoplasm (C) shows only a slight condensation. Surrounding thecal cells appear normal. $\times 7500$.

Fig. 2. Two apoptotic bodies (A) being phagocytosed by thecal cells. The body on the right is only partly surrounded by thecal cell cytoplasm (C), while that on the left is enclosed in a thin rim of cytoplasm. Other apoptotic bodies (arrows) can be seen at upper left and lower right. From a $1.8 \mathrm{~mm}$-diameter follicle in tertiary atresia. $\times 7500$.

Fig. 3. Two large apoptotic bodies (A) enclosed within the cytoplasm of a thecal cell whose nucleus (N) is at lower left. These bodies show degradative changes relative to those in Fig. 2, and the membrane (arrow) bounding the upper body is clearly visible. Smaller membrane-bounded bodies containing degenerating cellular material are also present. From the same follicle as in Fig. $1 . \times 7500$.

Fig. 4. Thecal capillary from a $2.6 \mathrm{~mm}$-diameter follicle in primary atresia. The endothelium (E) appears normal, but the lumen is filled with cellular material showing features of the first stage of apoptosis. Two nuclear fragments $(N)$ are present, one showing crescentic margination. $\times 7500$. 

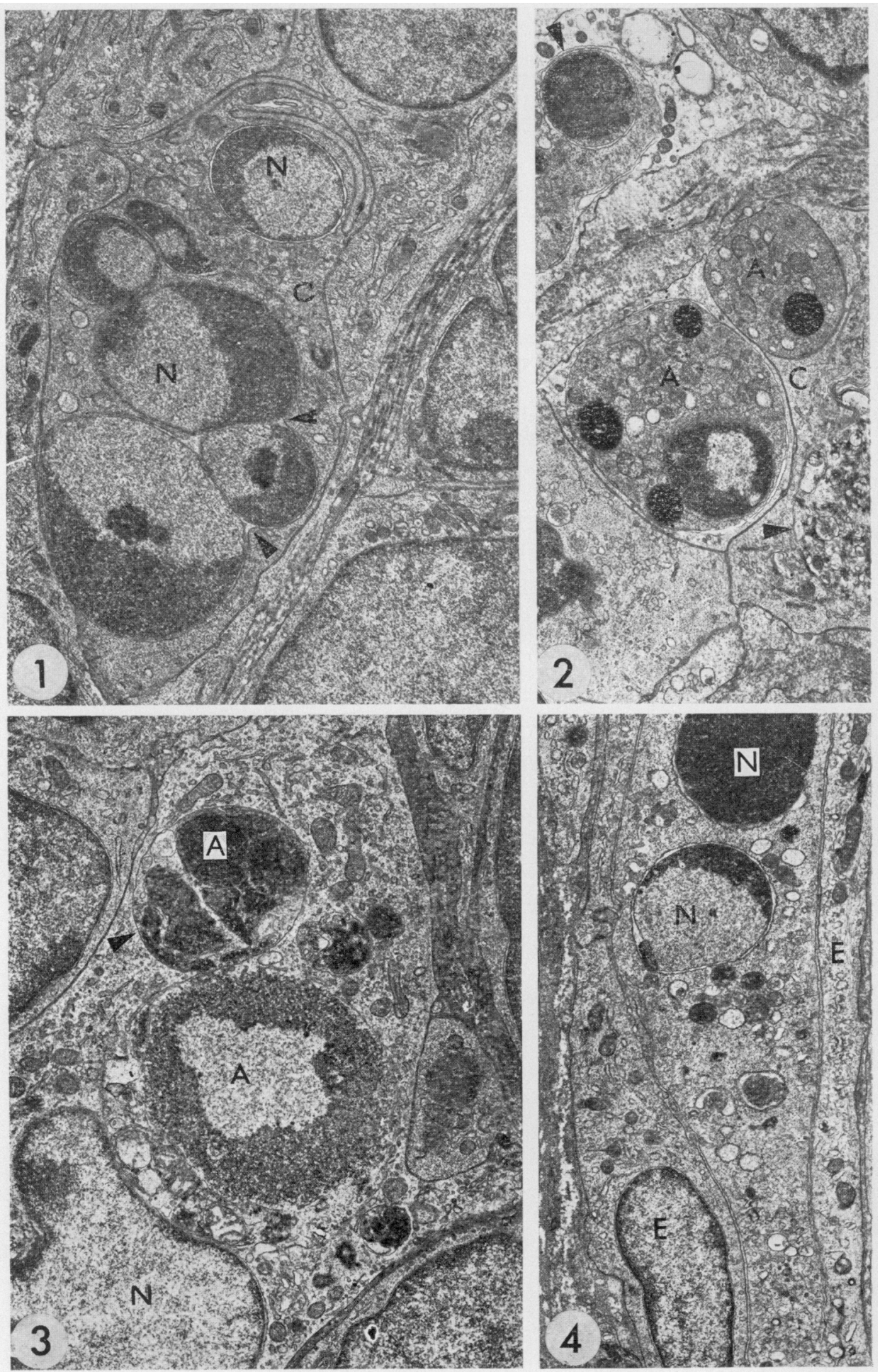

(Facing p. 184) 


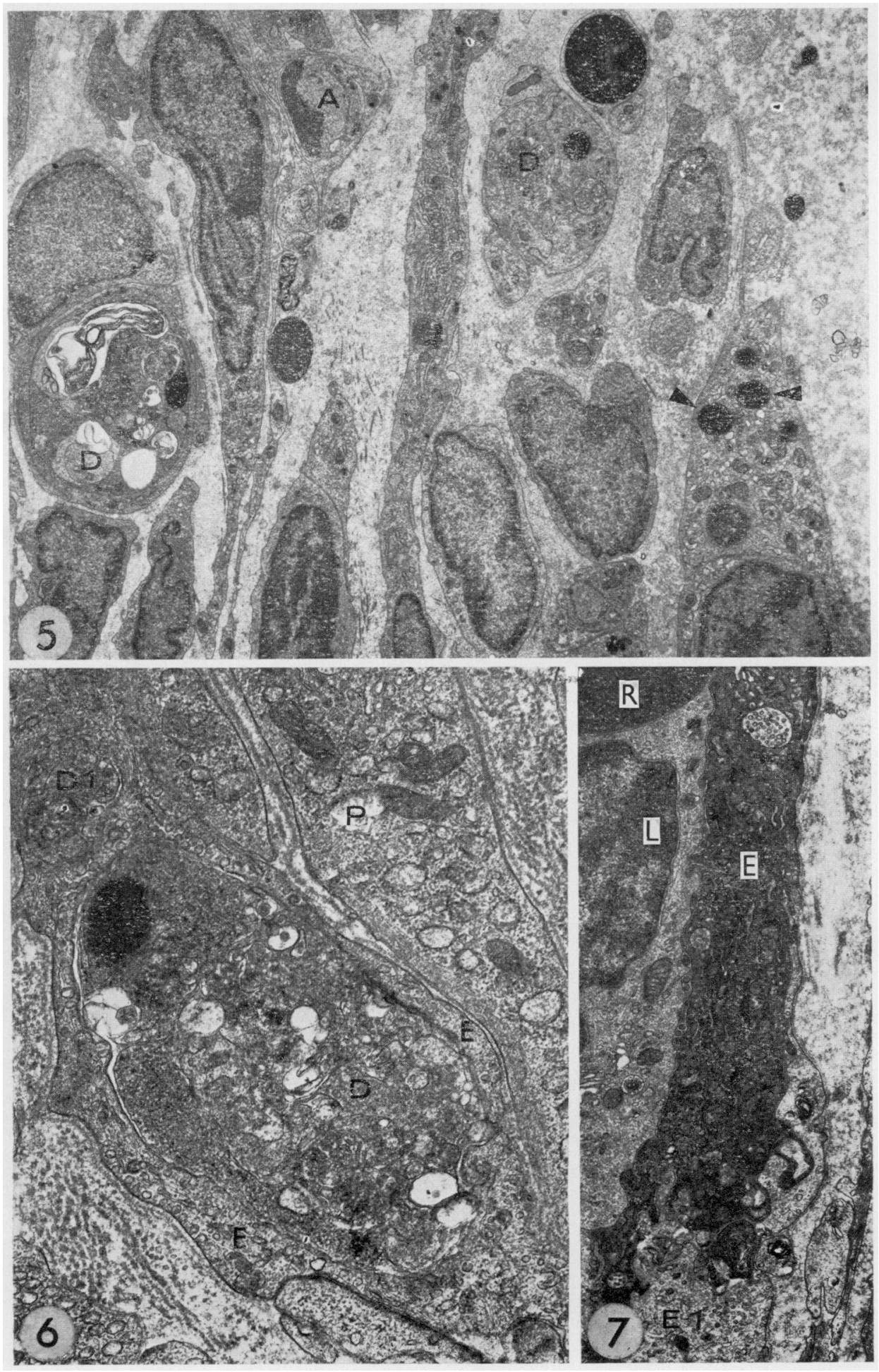


Additional changes observed during secondary atresia included an increase in cytoplasmic lipid droplets in the thecal cells, and an increasing irregularity of cellular and nuclear outlines. Cells rich in tubular ER remained in similar proportions to those in primary atresia, and in some follicles the thecal cells were separated by increased amounts of collagen-containing intercellular matrix.

During tertiary atresia there was a further progression of the changes described above. The shape of the thecal cells and their nuclei was now quite irregular and the cells were widely separated by ground substance containing collagen (Pl. 2, Fig. 5; compare with Fig. 5 of O'Shea et al., 1978). Lipid droplets were numerous, and apoptotic bodies were present in various numbers. Thecal structure showed more between-follicle variability in the degree of the degenerative changes present than at earlier stages. Overall, however, the theca interna was reduced in thickness, in extreme cases to as little as about 4 cells thick, and the proportion of cells rich in tubular ER was reduced to approximately $20 \%$. In some follicles the theca interna contained several almost rounded cells, possibly macrophages, whose cytoplasm was packed with lysosome-like granules of variable size.

\section{Changes in capillaries}

As described previously (Hay et al., 1976), thecal capillaries were concentrated in the inner region of the theca interna. Changes were observed occasionally in primary atresia, and progressively more frequently in secondary and tertiary atresia. The principal change at all stages was the appearance of degenerating cellular material, very similar to the extravascular apoptotic bodies described above, within the lumina of capillaries (Pl. 1, Fig. 4; PI. 2, Figs 5 and 6). These bodies generally lay free in the lumen, in an extracellular position, but were sometimes apparently enclosed within the cytoplasm of endothelial cells (Pl. 2, Fig. 6). Such bodies could, however, have been in contact with the lumen in other planes.

The origin of these intravascular cell fragments, which frequently contained nuclear remnants (Pl. 1, Fig. 4), was not clear. The walls of affected capillaries were consistently intact, and no evidence of the passage of apoptotic bodies through the capillary walls was detected. Occasionally endothelial cells showed a marked cytoplasmic condensation (Pl. 2, Fig. 7) suggestive of the early stage of apoptosis, but clear evidence of fragmentation of such cells into the lumen was not seen.

By the time that severe structural changes in the theca interna were evident in tertiary atresia, the capillary bed in the inner part of this layer appeared to be reduced, and many of the remaining capillaries were plugged with cellular debris. There was also an increase in the incidence of larger blood vessels, of arteriolar or venular dimensions, within the inner part of the theca in some of these follicles.

\section{Discussion}

The degenerative changes observed in many theca interna cells in this study conformed precisely with those described by Kerr et al. (1972) as characteristic of apoptosis. This term was applied by these

\section{EXPLANATION OF PLATE 2}

Fig. 5. Entire width of the theca interna from a $4.2 \mathrm{~mm}$-diameter follicle in tertiary atresia. The membrana granulosa (right) is entirely missing at this point in the follicular wall. The cells of the theca interna are widely separated, and show great variability in nuclear and cytoplasmic outlines. An apoptotic body (A), and degenerating cellular material (D) filling the capillary lumina, are present. A cell at the right contains several electron-dense lipid droplets (arrows). $\times 4800$.

Fig. 6. Part of the wall of a thecal capillary from a $4.2 \mathrm{~mm}$-diameter follicle in tertiary atresia, showing normal endothelium (E) and degenerating cellular material (D) filling the lumen. A small mass of similar material (D1) is apparently enclosed within the cytoplasm of an endothelial cell. A pericyte (P) is also present. $\times 18900$.

Fi. 7. Part of the wall of a capillary from a $4.2 \mathrm{~mm}$-diameter follicle in tertiary atresia. One endothelial cell (E) shows marked cytoplasmic condensation, while the adjoining endothelial cell (E1) appears norma1. A leucoctye (L) and an erythrocyte (R) are present in the lumen. $\times 8000$. 
authors to describe a rapid process by which individual cells are deleted in many normal and pathological tissues. Cell deletion, particularly during secondary and tertiary atresia, is therefore clearly an important feature of atresia in ovine follicles as it affects the theca interna. Putative steroidogenic cells, with tubular ER-rich cytoplasm, appeared to be selectively reduced in numbers in tertiary atresia, leading to a thecal structure similar to that described by Rajakoski (1960) and Marion, Gier \& Choudary (1968) as characterizing certain forms of atresia in the bovine ovary.

As in the bovine ovary (Priedkalns, Weber $\&$ Zemjanis, 1968), no evidence was seen of thecal cells giving rise to interstitial gland tissue or to corpora lutea atretica. However, a transient increase was noted in the proportion of tubular ER-rich cells in the early stages of atresia. This increase, which appeared to provide one of the earliest structural features of atresia, may have represented a precocious form of thecal differentiation in small atretic follicles. However, the possibility that these follicles might have already shrunk from a size at which tubular ER-rich cells are normally more numerous (O'Shea et al., 1978) could not be excluded.

The first evidence of thecal apoptosis was seen in primary atresia, indicating that thecal degeneration commences as soon as the membrana granulosa begins to degenerate. However, thecal changes were at all stages less widespread and less severe than those in the granulosa. In many respects the structural changes in thecal cells were similar to those reported previously for granulosa cells (Hay et al., 1976). Differences in the efficiency of disposal of fragments of dead cells, possibly associated with the absence of any vasculature in the granulosa, may have been responsible for the greater accumulation of free cellular debris, and the formation of giant atretic bodies, in the latter.

In spite of the marked structural changes which occur during atresia in the theca interna, it has been shown that tertiary atretic follicles do contain, and can secrete in vitro, considerable quantities of steroid hormones (Moor, Hay, Cran \& Dott, 1978). Therefore, steroidogenic cells must persist, at least in many atretic follicles, even into the more advanced stages of atresia. The presence of these cells in the theca accords well with previous findings that the predominant steroids secreted by atretic follicles are androgens (Moor et al., 1978), and furthermore Moor (1977) has shown that androgens are almost exclusively of thecal origin.

Changes in thecal capillaries during atresia were closely similar to those observed in luteal capillaries during regression (O'Shea, Nightingale \& Chamley, 1977). In the corpus luteum, where capillaries are far more abundant, evidence of an origin of intraluminal cell debris from endothelial degeneration was found. A similar origin for debris in the thecal capillaries seems probable, and our inability to establish this unequivocally may reflect the greater sampling problem arising in the study of follicular capillaries. Even in the corpus luteum, the majority of capillaries containing cellular debris possessed an intact endothelium (O'Shea et al., 1977).

The cause of these changes in thecal capillaries is not known. However, their presence presumably indicates stasis in affected vessels and must have contributed to the reduction in extent of the inner vascular network reported previously (Hay et al., 1976). Although this network is mainly distributed within the inner part of the theca interna, there was no indication of any focal deletion of thecal cells in that area. Nevertheless, since capillary changes are first detectable during primary atresia it is still likely that vascular changes play a major role in the atretic process.

We thank Dr R. M. Moor for performing the ovariectomies.

\section{References}

Brambell, F.W.R. (1956) Ovarian changes. In Marshall's Physiology of Reproduction, 3rd edn, Vol. 1, Part 1, pp. 397-542. Ed. A. S. Parkes. Longmans, London.

HAY, M.F., CRAN, D.G. \& MoOR, R.M. (1976) Structural changes occurring during atresia in sheep ovarian follicles. Cell Tiss. Res. 169, 515-529.
KerR, J.F.R., Wyllie, A.H. \& CURRIe, A.R. (1972) Apoptosis: a basic biological phenomenon with wide ranging implications in tissue kinetics. $\mathrm{Br} . J$. Cancer 26, 239-257.

Marion, G.B., GifR, H.T. \& Choudary, J.B. (1968) Micromorphology of the bovine ovarian follicular system. J. Anim. Sci. 27, 451-465. 
MOOR, R.M. (1977) Sites of steroid production in ovine Graafian follicles in culture. J. Endocr. 73, 143-150.

MOOR, R.M., HAY, M.F., Cran, D.G. \& DotT, H.M. (1978) Macroscopic identification and steroidogenic function of atretic follicles in sheep. $J$. Endocr. 77, 309-318.

Mossman, H.W. \& Duke, K.L. (1973) Comparative Morphology of the Mammalian Ovary. University of Wisconsin Press, Madison.

O'Shea, J.D., Nightingale, M.G. \& Chamley, W.A. (1977) Changes in small blood vessels during cyclical luteal regression in sheep. Biol. Reprod. 17, 162-177.
O'ShEA, J.D., CRAN, D.G., HAY, M.F. \& MOOR, R.M. (1978) Ultrastructure of the theca interna of ovarian follicles in sheep. Cell Tiss. Res. 187, 457-472.

Priedkalns, J., Weber, A.F. \& Zemuanis, R. (1968) Qualitative and quantitative morphological studies of the cells of the membrana granulosa, theca interna and corpus luteum of the bovine ovary. Z. Zellforsch. mikrosk. Anat. 85, 501-520.

RAJAKOSKI, E. (1960) The ovarian follicular system in sexually mature heifers with special reference to seasonal, cyclical and left-right variations. Acta endocr., Copenh., Suppl. 52, 1-68.

Received 9 February 1978 